\section{Case Reports in Neurology}

Case Rep Neurol 2021;13:53-58

DOI: 10.1159/000509859

Published online: January 28, 2021
(C) 2021 The Author(s) www.karger.com/crn

This article is licensed under the Creative Commons Attribution-NonCommercial 4.0 International License (CC BY-NC) (http://www.karger.com/Services/OpenAccessLicense). Usage and distribution for commercial purposes requires written permission.

\title{
Very-Late-Onset Neuromyelitis Optica Spectrum Disorder in a Patient with Breast Cancer and Parkinson Disease
}

\author{
Yasutaka Tajima Yukako Sone Hiroaki Yaguchi Yasunori Mito \\ Department of Neurology, Sapporo City General Hospital, Sapporo, Japan
}

\section{Keywords}

Neuromyelitis optica spectrum disorder · Anti-aquaporin-4 antibody · Breast cancer .

Parkinson disease

\begin{abstract}
Anti-aquaporin-4 (anti-AQP-4) antibody-positive neuromyelitis optica spectrum disorder (NMOSD) is a rare autoimmune disorder resulting in severe, recurrent optic neuritis, transverse myelitis, brain stem syndrome, and other types of neurological involvement. Its median age of onset has been reported to be around 40 years. We report herein a case of very-lateonset NMOSD (76 years of age) and try to promote its awareness as a type of neurological deterioration in elder patients. A 76-year-old woman suffering from Parkinson disease was admitted to our hospital because of consciousness disturbance. Cranial magnetic resonance imaging revealed the presence of fluid-attenuated inversion recovery high-signal-intensity lesions in the right peri- and intralateral ventricle. Part of this lesion and the meninges showed gadolinium enhancement. Physical examination revealed the presence of a tumor in the right breast, which was later diagnosed as invasive ductal carcinoma. In addition, laboratory examinations led to the detection of anti-AQP-4 antibodies in her serum; consequently, the patient was diagnosed as having NMOSD. She received initial pulsed steroid therapy, followed by right mastectomy. Although the patient's consciousness improved significantly, she developed abrupt-onset bilateral leg weakness and multiple longitudinal spinal cord lesions.
\end{abstract}

\begin{tabular}{ll}
\hline & Yasutaka Tajima \\
Department of Neurology & Sapporo City General Hospital \\
& N11.W13 Chu-o-ku, 060-8604 Sapporo (Japan) \\
yasutaka.tajima@doc.city.sapporo.jp
\end{tabular}




\section{Case Reports in Neurology}

Case Rep Neurol 2021;13:53-58

DOI: $10.1159 / 000509859$

(c) 2021 The Author(s). Published by S. Karger AG, Basel www.karger.com/crn

Tajima et al.: Very-Late-Onset NMOSD

Additional steroid therapy ameliorated the patient's leg weakness and reduced the swelling of the spinal cord.

(C) 2021 The Author(s)

Published by S. Karger AG, Basel

\section{Introduction}

Neuromyelitis optica spectrum disorder (NMOSD) is characterized by the preferential involvement of the optic nerves and spinal cord with positivity for anti-aquaporin-4 (anti-AQP4) antibodies [1,2]. This disease often presents in the fourth decade of life and exhibits female predominance. In rare instances, NMOSD has been reported in elderly persons (over 50 years of age), and the clinical entity of late-onset NMOSD has been mentioned [3]. Compared with early-onset NNOSD (below 50 years of age), late-onset NMOSD may exhibit characteristic features, especially those associated with aging or other non-neurological issues [4-8]. Here, we report a case of very-late-onset NMOSD in an elderly patient (76 years of age) with breast cancer and Parkinson disease who exhibited an unusual disease course.

\section{Case Report/Case Presentation}

The patient was a 76-year-old woman who had been suffering from Parkinson disease for 5 years. She had Stage III disease, as assessed using the Hoehn and Yahr (H-Y) Scale, and exhibited a stable condition under the control of l-dopa and dopamine agonists. Two weeks prior to admission, the patient became speechless gradually and spent most of the day in bed. Thus, she was admitted to our hospital for further evaluations. The patient exhibited worsening of bradykinesia and cogwheel rigidity. She required guardian's support for everyday life and was diagnosed with H-Y stage IV. She could walk with minimal assistance. Most strikingly, her consciousness level was impaired and estimated to be Glasgow Coma Scale (GCS) E3V3M5. Involvement of the cranial nerves or cerebellar dysfunction was not obvious. No clinical evidence obtained at that time indicated the involvement of the spinal cord. In addition to the neurological disturbances, a tumor was observed in the right breast, which was later pathologically proven to be invasive ductal carcinoma. Cranial fluid-attenuated inversion recovery (FLAIR) magnetic resonance imaging (MRI) examination revealed a high-signal-intensity lesion in the right peri- and intralateral ventricle (Fig. 1a, b). Part of this lesion and the meninges exhibited gadolinium enhancement (Fig. 1c, d). Cerebrospinal fluid (CSF) examination demonstrated the presence of pleocytosis $\left(159\right.$ cells $\left./ \mathrm{mm}^{3}\right)$ and an increased protein content (171 $\mathrm{mg} / \mathrm{dL}$ ). A cytological analysis was negative and no significant viral antibody titers were detected. Moreover, no bacterial cultures were obtained. The levels of the myelin basic protein were normal ( $88 \mathrm{pg} / \mathrm{mL}$; normal $<102 \mathrm{pg} / \mathrm{mL}$ ) and no oligoclonal bands were observed. AntiAQP-4 antibodies were detected $(28.5 \mathrm{U} / \mathrm{mL}$; normal, $<3 \mathrm{U} / \mathrm{mL})$ in her serum, whereas various auto-antibodies that indicate paraneoplastic neurological syndromes, such as anti-Yo, anti-Hu, Ro, and others, were negative. Based on these findings, the patient was diagnosed as having late-onset anti-AQP-4 antibody-positive NMOSD with invasive ductal carcinoma and 5-year history of Parkinson disease. Optic neuritis was not observed at that time. The patient received pulsed steroid therapy as the initial treatment, which improved her consciousness level significantly, to GCS E4V4M6. The abnormal signal alterations on MRI also improved (Fig.

\section{Karger'=}




\section{Case Reports in Neurology}

Case Rep Neurol 2021;13:53-58 DOI: $10.1159 / 000509859$

(c) 2021 The Author(s). Published by S. Karger AG, Basel www.karger.com/crn

Tajima et al.: Very-Late-Onset NMOSD

1e, f). The results of CSF examination indicating the presence of 32 cells $/ \mathrm{mm}^{3}$ and an elevated protein contents of $100 \mathrm{mg} / \mathrm{dL}$ were considered to represent partial improvement. After the initial pulsed steroid treatment, the patient received total mastectomy and further rehabilitation therapy for Parkinson disease. Two weeks after the mastectomy, she developed abruptonset bilateral leg weakness and walking difficulties; therefore, involvement of the spinal cord was suspected. MRI of the spinal cord revealed the presence of multiple spindle-shaped T2 high-signal-intensity alterations that were indicative of myelitis (Fig. 2a, b). Thus, pulsed steroid therapy was administered again, after which the MRI signal alterations of the spinal cord were reduced (Fig. 2c) and the patient's leg muscle strength improved. The patient refused further treatment, such as plasma exchange or other immune-modifying medications. Subsequently, the patient was transferred to another hospital for further rehabilitation.

\section{Discussion/Conclusion}

NMOSD is an autoimmune inflammatory central nervous system disorder that is typically associated with longitudinally extensive myelitis and optic neuritis [1,2]. Several studies have described the importance of the age at the onset of NMOSD; therefore, clinical differences might exist between late-onset (age at disease onset, $>50$ years) and early-onset NMOSD (age at disease onset, $<50$ years) NMOSD. Late-onset NMOSD may often be comorbid with age-related conditions compared with early-onset NMOSD [6]. Moreover, elderly patients have a tendency for a rapid worsening of their condition and poor response to immunomodulatory therapies [5, 7]. Therefore, an immediate diagnosis and awareness of the possibility of NMOSD in elderly patients are necessary [8]. At our institution, 12 cases of anti-AQP-4 antibody-positive NMOSD were confirmed over the past 10 years, with the present case being the oldest patient with NMOSD being followed at our hospital. In this single institution, half of the cases of NMOSD with anti-AQP-4 antibody positivity occurred in patients in their 40s. The age at onset was 50 years in 3 cases and 60 years in 2 cases. There were no other cases of NMOSD with an age at onset $>70$ years. Moreover, no other NMOSD cases had carcinoma and neurodegenerative disorders, such as Parkinson disease. In our case, we also suspected the paraneoplastic neurological symptom as the differential diagnosis, but various anti-neural-specific antibodies associated with paraneoplastic syndrome were not found [9]. In addition, the spinal cord involvement developed after the mastectomy. Regarding the paraneoplastic neurological symptoms, the initial treatment consisted in the suppression of tumor activity; therefore, its resection was considered to be most effective. The observation that the patient developed new neurological deterioration because of the spinal cord involvement after tumor removal seemed inconsistent with paraneoplastic syndrome. Band-like lesions in the lateral ventricle and the linear enhancement of the ependymal surface of the lateral ventricle were characteristic MRI findings in this case. The meninges were also enhanced. These MRI abnormalities have been previously reported in patients with NMOSD [10]. Based on these findings, we considered that the newly emerging neurological symptoms observed in the current patient were caused by NMOSD.

In conclusion, we described the clinical features of a rare case of very-late-onset NMOSD and attempted to promote awareness of NMOSD in elderly patients with neurological deterioration.

\section{Karger'=}




\section{Case Reports in Neurology}

\begin{tabular}{l|l}
\hline Case Rep Neurol 2021;13:53-58 \\
\hline DOI: 10.1159/000509859 & $\begin{array}{l}\text { ( ) 2021 The Author(s). Published by S. Karger AG, Basel } \\
\text { www.karger.com/crn }\end{array}$ \\
\hline
\end{tabular}

Tajima et al.: Very-Late-Onset NMOSD

\section{Acknowledgements}

The authors would like to thank Enago (www.enago.jp) for the English language review.

\section{Statement of Ethics}

The patient provided both oral and written informed consent for the publishing of this report (including images).

\section{Conflict of Interest Statement}

The authors have no conflict of interest to declare.

\section{Funding Sources}

The authors have no funding sources to disclose.

\section{Author Contributions}

Y.T. designed the case report and wrote the manuscript. All authors were equally involved in the medical management of the patient and approved final version of the manuscript.

\section{References}

1 Wingerchuk DM, Banwell B, Bennett JL, Cabre P, Carroll W, Chitnis T, et al.; International Panel for NMO Diagnosis. International consensus diagnostic criteria for neuromyelitis optica spectrum disorders. Neurology. 2015 Jul;85(2):177-89.

2 Weinshenker BG, Wingerchuk DM. Neuromyelitis spectrum disorders. Mayo Clin Proc. 2017 Apr;92(4):66379.

3 Carnero Contentti E, Daccach Marques V, Soto de Castillo I, Tkachuk V, Ariel B, Castillo MC, et al. Clinical features and prognosis of late-onset neuromyelitis optica spectrum disorders in a Latin American cohort. J Neurol. 2020 May;267(5):1260-8.

4 Sepulveda M, Delgado-García G, Blanco Y, Sola-Valls N, Martinez-Lapiscina EH, Armangué T, et al. Late-onset neuromyelitis optica spectrum disorder: the importance of autoantibody serostatus. Neurol Neuroimmunol Neuroinflamm. 2019 Aug;6(6):e607.

5 Krumbholz M, Hofstadt-van Oy U, Angstwurm K, Kleiter I, Jarius S, Paul F, et al. Very late-onset neuromyelitis optica spectrum disorder beyond the age of 75. J Neurol. 2015 May;262(5):1379-84.

6 Fragoso YD, Ruocco HH, Dias RM, Cabeça H, Gonçalves R, de Carvalho Sousa NA, et al. Late Onset of Neuromyelitis Optica Spectrum Disorders. Neurol Ther. 2019 Dec;8(2):477-82.

7 Sechi E, Addis A, Batzu L, Mariotto S, Ferrari S, Conti M, et al. Late presentation of NMOSD as rapidly progressive leukoencephalopathy with atypical clinical and radiological findings. Mult Scler. 2018 Apr;24(5):685-8.

8 Otani T, Irioka T, Takahashi YK, Soga K, Igarashi S, Kaneko K, et al. Two cases of late-onset neuromyelitis optica spectrum disorder initially presenting with isolated cerebral white matter lesions. eNeurologicalSci. 2018 Nov;13:35-7.

9 Graus F, Dalmau J. Paraneoplastic neurological syndromes. Curr Opin Neurol. 2012 Dec;25(6):795-801. 


\section{Case Reports in Neurology}

\begin{tabular}{l|l}
\hline Case Rep Neurol 2021;13:53-58 \\
\hline DOI: 10.1159/000509859 & $\begin{array}{l}\text { @ 2021 The Author(s). Published by S. Karger AG, Basel } \\
\text { www.karger.com/crn }\end{array}$ \\
\hline
\end{tabular}

Tajima et al.: Very-Late-Onset NMOSD

10 Kim HJ, Paul F, Lana-Peixoto MA, Tenembaum S, Asgari N, Palace J, et al.; Guthy-Jackson Charitable Foundation NMO International Clinical Consortium \& Biorepository. MRI characteristics of neuromyelitis optica spectrum disorder: an international update. Neurology. 2015 Mar;84(11):1165-73.
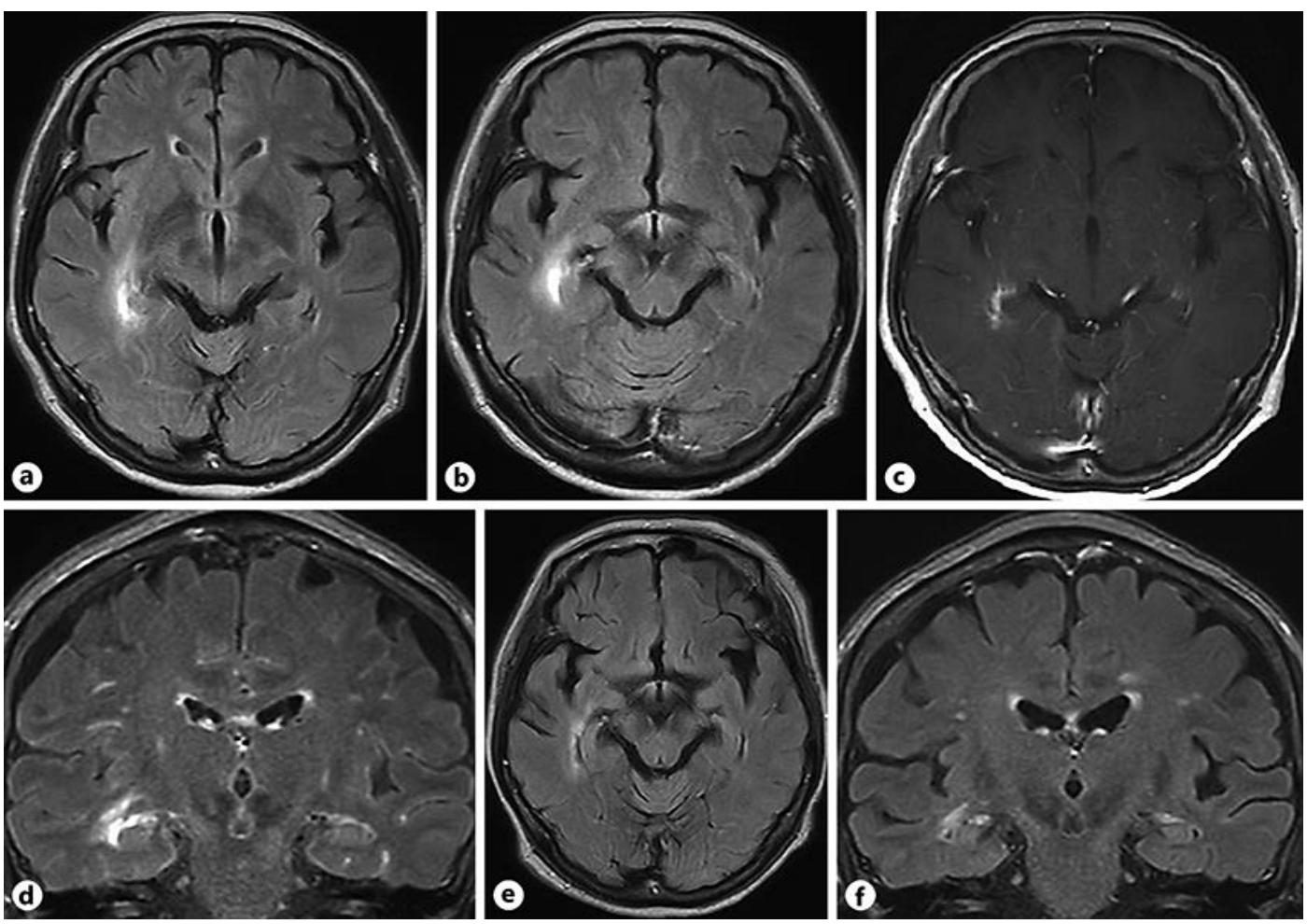

Fig. 1. a, b FLAIR MRI showing a high-signal-intensity right peri- and intralateral ventricle lesion. This lesion showed partial gadolinium enhancement (c), and meningeal enhancement was also observed (d). After steroid treatment, the FLAIR high-signal-intensity ventricular lesion appeared to be smaller (e), and the meningeal enhancement disappeared (f). 


\section{Case Reports in Neurology}

\begin{tabular}{l|l}
\hline Case Rep Neurol 2021;13:53-58 \\
\hline DOI: 10.1159/000509859 & $\begin{array}{l}\text { (c) 2021 The Author(s). Published by S. Karger AG, Basel } \\
\text { www.karger.com/crn }\end{array}$ \\
\hline
\end{tabular}

Tajima et al.: Very-Late-Onset NMOSD
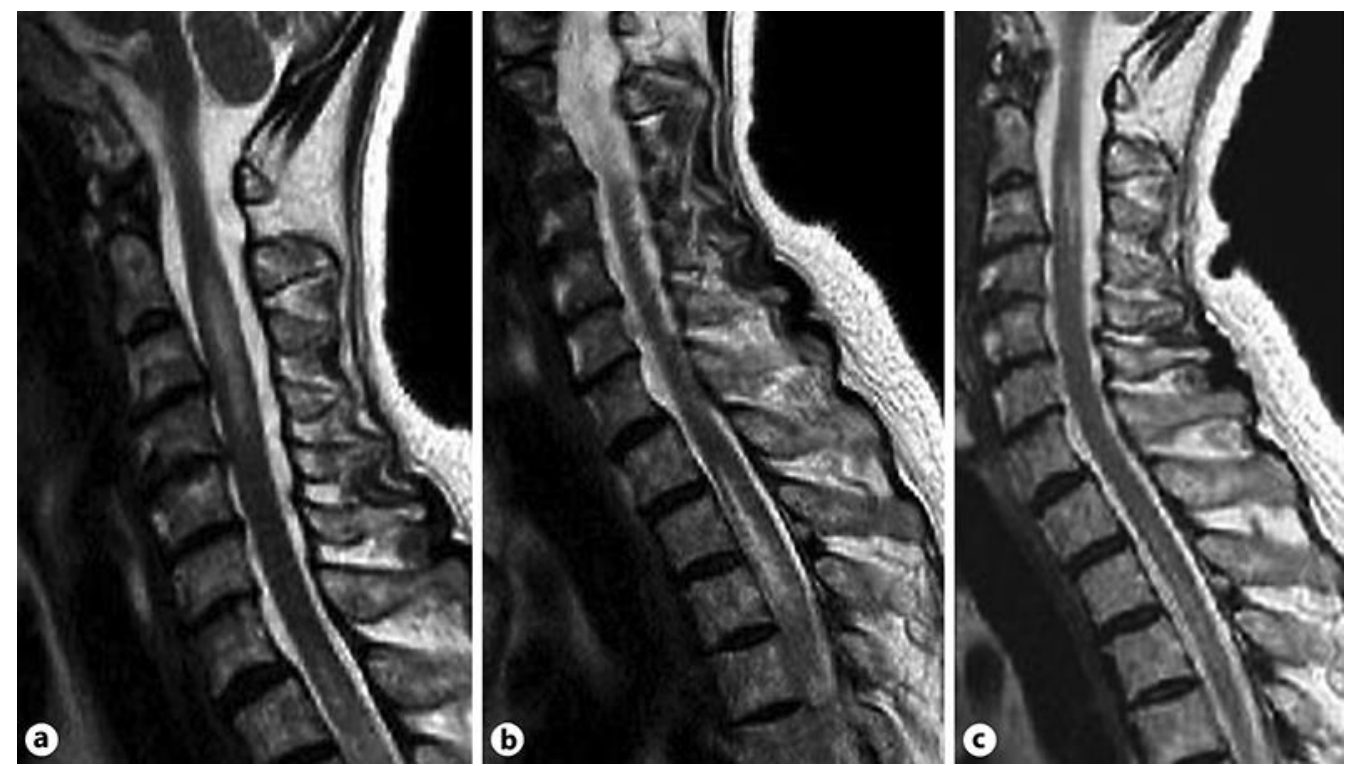

Fig. 2. At the time of development of lower-limb weakness, T2 high-signal-intensity lesions were observed at the C2-4 (a) and T1-4 (b) levels, with spinal cord swelling. c After the second steroid treatment, both lesions looked less prominent, and the spinal cord swelling disappeared. 